\title{
Exposure to excess dissolved iron in vivo affects oxidative status in the bivalve Mya arenaria
}

\author{
Paula M. González a ${ }^{\text {, Doris Abele }}{ }^{\mathrm{b}}$, Susana Puntarulo ${ }^{\mathrm{a}, *}$ \\ a Physical Chemistry-PRALIB, School of Pharmacy and Biochemistry, University of Buenos Aires, Junin 956, 1113 Buenos Aires, Argentina \\ b Alfred Wegener Institute for Polar and Marine Research, Department of Functional Ecology, Am Handelshafen 12, 27570, Bremerhaven, Germany
}

\section{A R T I C L E I N F O}

Article history:

Received 11 January 2010

Received in revised form 4 April 2010

Accepted 5 April 2010

Available online 14 April 2010

\section{Keywords:}

Iron overload

Labile iron pool

Mya arenaria

Oxidative stress

\begin{abstract}
A B S T R A C T
The effect of in vivo Fe exposure on the oxidative metabolism of the bivalve Mya arenaria was studied. Fe was supplemented in natural seawater and resulted in a significant increase in the total Fe content in the bivalve digestive gland (DG) between 9 to 17 days of exposure. Mortality of treated animals increased drastically after day 18. Oxidative stress conditions were characterized in DG through assessment of the generation of reactive oxygen species (ROS) and ascorbyl radical $(A \bullet)$ content. Both parameters were affected following a biphasic profile showing significant increases by days 2 and 9 of Fe exposure. The content of 2-thiobarbituric acid reactive substances (TBARS) was significantly increased over control values by days 2, 9 and 17 of treatment. The labile Fe pool (LIP) in isolated DG was elevated over control values by day 7, and maintained this increase until day 17 of Fe exposure. The content of NO, assessed by EPR spin trapping, was 60\% lower in DG of animals exposed for 2 days to Fe than in control values, with no further changes. The biphasic profile of oxidative stress response to Fe exposure in DG suggests that at early stages of Fe supplementation the cellular control mechanisms, such as CAT activity, were operative to limit oxidative damage, but further Fe exposure overwhelmed these abilities. Moreover, the second phase could be understood as the consequence of the exhaustion of cellular protective systems that could also involve NO.
\end{abstract}

(c) 2010 Elsevier Inc. All rights reserved.

\section{Introduction}

Marine filters and deposit feeders ingest Fe bound to dissolved and particulate matter in the water column and the sediment surface. Among the filter feeders, bivalves are regarded especially useful as bioindicators of pollution, as ingested metals can accumulate in both their soft tissues and calcium carbonate shells (Tynan et al., 2005). Relatively high Fe concentrations were detected in tissues of Antarctic macrofauna such as the Antarctic soft shell clam Laternula elliptica (Estévez et al., 2002). These bivalves colonize coastal waters ( $28 \mathrm{mg} \mathrm{Fe}$ / $\mathrm{g}$ DM sediment) in West Antarctica and are enriched in Fe compared to bivalves of similar ecotype, Mya arenaria, colonizing less Fe charged regions ( $7.5 \mathrm{mg} \mathrm{Fe} / \mathrm{g} \mathrm{DM}$ sediment) of the European Wadden Sea (Estévez et al., 2002).

Fe is a micronutrient, essential for growth and cellular functioning (Templeton and Liu, 2003) and is also involved as catalytic agent in many biochemical reactions. Fe is found in tissues, both as a catalytically

Abbreviations: AU, arbitrary units; CAT, catalase; EDTA, ethylenediaminetetraacetic acid; EPR, electronic paramagnetic resonance; DM, dry mass; DMSO, dimethylsulfoxide; FM, fresh mass; HPLC, high performance liquid chromatography; IFW, iron free water; SOD, superoxide dismutase.

* Corresponding author. Fisicoquímica, Facultad de Farmacia y Bioquímica, Junín 956, Buenos Aires, C1113AAD, Argentina. Tel.: +54 114964 8244x101; fax: + 54114508 $3646 \times 102$.

E-mail address: susanap@ffyb.uba.ar (S. Puntarulo). inactive element not directly available to biochemical reactions and often constitutes the active centre of electron transferring enzymes or is stored in specific Fe-binding proteins, such as ferritin. Further, there is a labile iron pool (LIP) within cells and body fluids. This fraction comprises a low-molecular-weight pool of weakly chelated Fe and represents the catalytically active Fe fraction in a tissue. On the one hand, this fraction potentially generates reactive oxygen species (ROS) since it catalyzes the conversion of normal by-products of cell respiration, such as hydrogen peroxide and superoxide anion, into highly damaging radical species (hydroxyl radical); and also the conversion of ascorbate $\left(\mathrm{AH}^{-}\right.$) to ascorbyl radical $\left(\mathrm{A}^{\circ}\right)$. On the other hand, the LIP serves as an intracellular source of Fe which satisfies the continuous demand for the synthesis of Fe-containing proteins. Thus, a permanent Fe flux from the extracellular medium to the cytoplasm is generated, and the nature and magnitude of the Fe trafficking and Fe toxicity features in the tissues are still under investigation. The potential for ROS production in molluscs is particularly significant in the lipid rich digestive gland (DG) which is a primary accumulation site for ingested transition metals (Geyer et al., 1982; González et al., 2008a, b). Moreover, hemocyte cells seem to be Fe sinks in invertebrates, and are possibly good indicators of the availability of Fe to animals. Fe circulation in the hemolymph is an early event in $\mathrm{Fe}$ distribution to the tissues after the initial incorporation into the DG (Ahearn et al., 2004).

Viarengo et al. (1999) exposed Mytilus galloprovincialis to $600 \mu \mathrm{g} / \mathrm{L}$ Fe and observed significant Fe accumulation in DG after 3 days of 
treatment. This Fe accumulation led to an increase in ROS generation, assessed as oxidation of dihydrorhodamine, and lipid peroxidation (2thiobarbituric acid reactive substances (TBARS) accumulation). More recently, Alves de Almeida et al. (2004) reported a significant increase in malondialdehyde (MDA) levels in DG of the mussel Perna perna exposed to $500 \mu \mathrm{g} / \mathrm{L}$ Fe during a 5 day period. The authors proposed the induction of phospholipid hydroperoxide glutathione peroxidase activity following the exposure to Fe overload, as a potentially new biomarker of toxicity associated with contaminant exposure in mussels.

Nitric oxide (NO) is a regularly occurring radical intermediate of many reactions mostly linked to its function as a signaling molecule (Davis et al., 2001), and it is also an endogenous chelator capable of binding Fe (Cooper, 1999). Thus, the NO-Fe complexes formed could favor Fe extrusion and alter Fe cellular distribution. Recently, we presented the first evidence for physiological NO generation in the soft shell clam $M$. arenaria, and for the involvement of nitric oxide synthase (NOS)-like enzymes in NO generation in the bivalve species (González et al., 2008a).

In the present study, the oxidative effects produced by an experimental increase of tissue Fe content were investigated in the bivalve $M$. arenaria. The species was chosen because the natural Fe concentrations in its tissues are lower as compared to the content in the Antarctic soft shell clam L. elliptica. The effect of in vivo Fe exposure on the oxidative status in DG of experimental animals was studied over a 17 day period. Oxidative stress condition possibly arising from $\mathrm{Fe}$ exposure was characterized by assessing ROS generation rate in the DG homogenates, the $A \cdot$ content, and the oxidative damage of lipids, as the content of thiobarbituric acid reactive substances (TBARS). The LIP in both, DG and hemocytes, was studied in order to correlate oxidative metabolism to the presence of catalytically active Fe in the tissues. The involvement of antioxidant enzymes in regulating Fe effects, such as CAT and SOD, was also evaluated. Moreover, since NO possibly affects the cellular distribution by its ability to chelate Fe, the NO content was assessed by EPR in tissue homogenates upon exposure to excess Fe.

\section{Materials and methods}

\subsection{Animal collection and maintenance}

Soft shell clams, M. arenaria L. (5.3 to $9.1 \mathrm{~cm}$ shell length and 3.2 to $6 \mathrm{~cm}$ shell width) were collected on an intertidal sand flat near Bremerhaven, Germany in May 2006. At the Alfred Wegener Institute, Bremerhaven, animals were kept in two aquaria with fully aerated natural seawater of $23-26 \%$ PSU, and at $10{ }^{\circ} \mathrm{C}$ for at least 1 week prior to the experiments, to ensure that animals were healthy and not stressed from sampling. The bottom of the aquaria was covered with pebble stones. Animals were fed live phytoplankton twice a week, using DT's live marine phytoplankton, premium reef blend consisting of Nannochloropsis oculata, Phaeodactylum sp., Tricornotum sp., Chlorella sp., between 2 and $20 \mu \mathrm{m}$ particle size with no Fe added.

\subsection{In vivo Fe exposure}

Experimental bivalves were placed in small aquaria containing $13 \mathrm{~L}$ ( $1 \mathrm{~L} /$ animal) of natural seawater of $23-26 \%$ at $10{ }^{\circ} \mathrm{C}$, and $500 \mu \mathrm{M}$ of Fe as Fe-EDTA complex (1:2). Fe-EDTA was used in this study as the Fe source both for the chemical nature of the complex and for its existence in natural waters. EDTA is known to react with metal cations and it has been proven that exchange reactions do occur in natural seawater (Hering and Morel, 1988). In the Fe incubation treatments seawater was replaced every two days by a fresh solution to assure for water quality and the constant Fe content in the medium. The animals were fed during experimentation until two or three days before killing. Sampling was performed at irregular intervals $(0,2,7,9$ and 17 days) after performing some preliminary measurements of $\mathrm{Fe}$ enrichment. Specimens were dissected and DG frozen and stored in liquid nitrogen.

\subsection{Total Fe content}

Total Fe content was analyzed by two independent techniques: (a) according to Bralet et al. (1992) with modifications: approximately $40 \mathrm{mg}$ of DG was homogenized in $1 \mathrm{~mL}$ of $150 \mathrm{mM} \mathrm{KCl}$ in $0.1 \mathrm{~N}$ $\mathrm{HCl}, \mathrm{pH} 2.5$, prepared with IFW. The samples were incubated for $24 \mathrm{~h}$ at $37^{\circ} \mathrm{C}$ in the presence of $9 \mathrm{mg} / \mathrm{mL}$ pepsin, $4.5 \mathrm{mM} \mathrm{2,2}$ ' dipyridyl and $103 \mathrm{mM}$ ascorbic acid, pH 7 prepared in IFW. For each sample both, a reactive blank, and a sample blank without adding $2,2^{\prime}$ dipyridyl were prepared. Absorbance at $\lambda=520 \mathrm{~nm}$ was measured. To determinate the Fe content, a standard curve was prepared with $\mathrm{Fe}$ in a concentration range from 0 to $120 \mu \mathrm{M}$; (b) by atomic absorption: approximately $700 \mathrm{mg}$ of $\mathrm{N}_{2}$ liquid frozen tissue was mineralized in a microwave oven for 2 cycles, with $2 \mathrm{~mL}$ of $\mathrm{HNO}_{3}$. The samples were diluted in $10 \mathrm{~mL}$ final volume with $40 \%$ (v/v) $\mathrm{HNO}_{3}$ in IFW. The Fe was determined by atomic absorption spectroscopy in air-acetylene flame at $\lambda=248.3 \mathrm{~nm}$, with a Varian SpectrAA 220 equipment. To determinate the Fe content, a standard curve was prepared with $\mathrm{Fe}$ in a concentration range from 0 to $54 \mu \mathrm{M}$. All the used materials were treated with $\mathrm{HNO}_{3}$ and IFW to avoid Fe contamination.

\subsection{Determination of glutathione content}

Glutathione content, as both reduced (GSH) and oxidized (GSSG) forms, was determined according to Fariss and Reed (1987) using high performance liquid chromatography (HPLC). Peaks were detected at $\lambda=365 \mathrm{~nm}$ with a photodiode array detector. Concentrations of GSH and GSSG were calculated using GSH and GSSG commercial standards, and then the GSSG/GSH ratio was calculated. Total glutathione content was calculated as indicated by Eq. 1 .

Total glutathione $=(\mathrm{GSSG} / \mathrm{mg} \mathrm{FM} \times 2)+\mathrm{GSH} / \mathrm{mg}$ FM

The $\mathrm{pH}$ in the DG was measured according to Pörtner et al. (1990) and the tissue redox potential $(\Delta E)$ was calculated based on Nernst's Eq. (2) and the tissue specific pH (Schafer and Buettner, 2001).

$\Delta E=\Delta E^{\circ}-(\mathrm{RT} / \mathrm{nF}) \ln [\mathrm{GSH}]^{2} /[\mathrm{GSSG}]$

\subsection{ROS production by tissue homogenates}

DG samples were homogenized $(1: 5 \mathrm{w} / \mathrm{v})$ in a $100 \mathrm{mM}$ Tris- $\mathrm{HCl}$, pH 7.75 buffer, with $2 \mathrm{mM}$ EDTA and $5 \mathrm{mM} \mathrm{MgCl}$ (Gallagher et al., 1992). Measurements were conducted according to Viarengo et al. (1999) with modifications. Briefly, the homogenates were centrifuged at $4{ }^{\circ} \mathrm{C}$ for $20 \mathrm{~min}$ at $10,000 \mathrm{~g}$ and the supernatants were employed. The reaction was followed in a $30 \mathrm{mM}$ HEPES, pH 7.2 buffer, with $200 \mathrm{mM} \mathrm{KCl}$ and $1 \mathrm{mM} \mathrm{MgCl}$. The fluorescent probe $2^{\prime}, 7^{\prime}$ dichlorofluorescein diacetate (DCFH-DA) was added to the buffer, in a final concentration of $40 \mu \mathrm{M}$. Then, after addition of 10 to $5 \mu \mathrm{L}$ of the supernatant, the reaction mixture was incubated at $35^{\circ} \mathrm{C}$ during $10 \mathrm{~min}$. The fluorescent compound DCF, generated by radicaldependent oxidation of the probe, was detected spectrofluorometrically at $\lambda_{\mathrm{ex}}=488 \mathrm{~nm}$ and $\lambda_{\mathrm{em}}=525 \mathrm{~nm}$. Protein content was calculated according to Lowry et al. (1951).

\subsection{Determination of $A \bullet$ content}

Measurements were performed at room temperature $\left(18^{\circ} \mathrm{C}\right)$ by EPR using a Bruker (Karlsruhe, Germany) spectrometer ECS 106 with a cavity ER 4102ST. Homogenates from DG were prepared in pure DMSO with $1 \mathrm{mM}$ desferroxamine (DF) (1:4) and immediately 
transferred to a Pasteur pipette for $\mathrm{A} \bullet$ detection. Instrument settings were as follows: $9.76 \mathrm{GHz}$ microwave frequency, $10 \mathrm{~mW}$ microwave power, $50 \mathrm{kHz}$ modulation frequency, $1 \mathrm{G}$ modulation amplitude, $3487 \mathrm{G}$ centered field, $327.68 \mathrm{~ms}$ time constant, $81.92 \mathrm{~ms}$ conversion time, $1 \cdot 10^{5}$ receiver gain and $15 \mathrm{G}$ sweep width. Quantification of the spin adduct was performed using an aqueous solution of 4hydroxy-2,2,6,6-tetramethylpiperidinyloxy (TEMPOL) introduced into the same sample cell used for the samples. EPR spectra for both, sample and TEMPOL solutions, were recorded at exactly the same spectrometer settings and the first derivative EPR spectra were double integrated to obtain the area intensity, from which the concentration of the radical was calculated according to Kotake et al. (1996).

\subsection{Determination of the content of $\mathrm{AH}^{-}$}

The content of $\mathrm{AH}^{-}$was measured by reverse phase HPLC with electrochemical detection. DG samples were homogenized in metaphosphoric acid 10\% (w/v) according to Kutnink et al. (1987). Commercially available $\mathrm{AH}^{-}$(Sigma, St Louis, USA) was used as standard.

\subsection{Determination of TBARS content}

BARS content in DG homogenates was measured according to Uchiyama and Mihara (1978), as described in Storch et al. (2001), and Abele et al. (2002). Malondialdehyde standards were prepared from 1,1,3,3-tetraethoxypropane.

\subsection{Determination of LIP in DG}

The LIP in isolated DG was determined by a fluorescence technique with the Fe sensor calcein (CA) according to Darbari et al. (2003) with modifications by Robello et al. (2007). DG was homogenized in $40 \mathrm{mM}$ potassium phosphate buffer, $120 \mathrm{mM} \mathrm{KCl}$, pH 7.4 (1:10). The homogenate was centrifuged at $8700 \mathrm{~g}$ for $15 \mathrm{~min}$ at $4{ }^{\circ} \mathrm{C}$ and the supernatant removed to Eppendorf tubes and centrifuged again at $8700 \mathrm{~g}$ for $15 \mathrm{~min}$ at $4{ }^{\circ} \mathrm{C}$. The supernatant was filtered through filters with 30,000 nominal molecular weight limit (Centricon YM30). The filtered solution was then reduced with equal volume of $8 \%(\mathrm{v} / \mathrm{v})$ thioglycolic acid. Fe in the reduced solution was measured using $1 \mu \mathrm{M}$ CA solution in $40 \mathrm{mM}$ potassium phosphate buffer, $120 \mathrm{mM} \mathrm{KCl}, \mathrm{pH}$ 7.4. When Fe is added to CA solution a fraction of the dye binds free $\mathrm{Fe}^{2+}$ leading to the generation of the Fe-bound (quenched) complex [CA-Fe], while another fraction remains free as unbound CA and provides the residual fluorescence. The fluorescence $\left(\lambda_{\text {exc }}=485 \mathrm{~nm}\right.$, $\lambda_{\mathrm{em}}=535 \mathrm{~nm}$ ) was recorded until stabilization of the signal $\left(F_{1}\right)$ and then deferoxamine (DF) was added to a final concentration of $1 \mathrm{mM}$. The fluorescence was monitored until a new stabilization of the signal $\left(F_{2}\right)$. The magnitude of the absolute change in fluorescence $\left(F_{2}-F_{1}\right)$ is equivalent to the amount of Fe bound to $C A$. The fractional increase of fluorescence $(\Delta F)$ that reflects the LIP concentration was calculated according to Eq. 3,

$\Delta F=\left(F_{2}-F_{1}\right) / F_{2}$

The LIP was assessed using Eq. 4 and a dissociation constant (Kd) value of $0.46 \mu \mathrm{M}$.

$\mathrm{LIP}=(\Delta F \times[\mathrm{CA}])+[(\mathrm{Kd} \times \Delta F) /(1-\Delta F)]$

\subsection{Determination of LIP in hemocytes}

To assess the LIP in hemocytes cells were withdrawn from the adductor muscle of the clams using a $1 \mathrm{~mL}$ plastic syringe with an hypodermic needle, after $0,2,7,9$ and 17 days of Fe exposure of the animals. The pooled haemolymph of two to three animals were stored in Eppendorf tubes on ice. Samples were centrifuged at $2000 \mathrm{~g}$ for $30 \mathrm{~s}$, the pellet was resuspended in washing medium consisted in $580 \mathrm{mM} \mathrm{NaCl}$, $11 \mathrm{mM} \mathrm{KCl}, 28 \mathrm{mM} \mathrm{MgSO}$, $25 \mathrm{mM} \mathrm{MgCl}, 11 \mathrm{mM} \mathrm{CaCl} 2,2.4 \mathrm{mM}$ $\mathrm{NaHCO}_{3}, 153 \mathrm{M}$ HEPES at pH 7.0. Then, the samples were centrifuged at $2000 \mathrm{~g}$ for $30 \mathrm{~s}$ and the pellet resuspended with a minimum of support medium consisting of the same washing medium with $0.1 \%(\mathrm{w} / \mathrm{v})$ glucose. Samples were observed under optical microscope to control the quality of the cells before used. Two to three pools were prepared for each experimental condition and more than 100 cells were analyzed in each case. The hemocytes in the support medium were loaded with $20 \mu \mathrm{M}$ Phen Green SK (PG) for $30 \mathrm{~min}$ at $4{ }^{\circ} \mathrm{C}$. The PG chelates the labile $\mathrm{Fe}$ in the cells. The cells were centrifuged at $2000 \mathrm{~g}$ for $20 \mathrm{~s}$ and the pellet was resuspended in supporting medium to wash away the PG. Cells were then analyzed by a Leica IRBE confocal laser scanning microscope and Leica TCS-NT software (Bensheim, Germany) equipped with a krypton/ argon laser to perform the fluorescence measurements. The objective lens was $63 \times$ (numerical aperture 1.2) and the microscope sample stage was cooled to $4{ }^{\circ} \mathrm{C}$. Green fluorescence of the PG SK was excited at $\lambda=488 \mathrm{~nm}$ at a laser intensity of $8 \mathrm{~mW}$ and the fluorescence emission was recorded using a $550 \mathrm{~nm}$ long pass filter. The pinhole was set at 1.0. Single-cell fluorescence was determined by manually defining the three dimensional regions of interest (a single cell) scanning vertically through the cell at a z-scan width of $1.2 \mu \mathrm{m}$. Image processing and evaluation were performed using the software of the Leica TCS imaging system. Afterwards, the labile Fe was removed from PG by the addition of an excess of the cell-permeable chelator DF $(5 \mathrm{mM})$. After $60 \mathrm{~min}$ of incubation of the cells in the presence of the chelator, fluorescence was assessed in the confocal microscope. Labile Fe concentration was determined from the cellular fluorescence by calculating the difference in fluorescence between DF charged cells and PG charged cells.

\subsection{Determination of antioxidant enzymes}

Homogenates from DG were prepared in $30 \mathrm{mM}$ potassium phosphate, $120 \mathrm{mM} \mathrm{KCl}, \mathrm{pH}$ 7.4. SOD activity (E.C. 1.15.1.1) was measured based on its capacity to inhibit the reduction of cytochrome c by superoxide radicals generated by a xanthine oxidase/xanthine system, at $\lambda=550 \mathrm{~nm}$ in $50 \mathrm{mM}$ potassium phosphate buffer with $0.1 \mathrm{mM}$ EDTA, pH 7.8, and $10 \mu \mathrm{M}$ xanthine and the amount of xanthine oxidase required to detect a change of 0.025 absorbance units $\mathrm{min}^{-1}$ according to McCord and Fridovich (1969). One Unit SOD was defined as the amount of tissue extract that gave 50\% inhibition of cytochrome $\mathrm{c}$ reduction under the assay conditions. Catalase activity (EC 1.11.1.6) was assayed spectrophotometrically by the decomposition of $\mathrm{H}_{2} \mathrm{O}_{2}$ at $\lambda=240 \mathrm{~nm}$ in a reaction mixture consisting of $50 \mathrm{mM}$ potassium phosphate buffer (pH 7.0) and $15 \mathrm{mM} \mathrm{H}_{2} \mathrm{O}_{2}$ (Aebi, 1984). Protein measurements were performed according to Lowry et al. (1951).

\subsection{Determination of the content of nitrate and nitrite}

The total content of nitrate and nitrite was assessed by the Griess reaction, according to Verdon et al. (1995) with modifications. The isolated DG was homogenized in $14 \mathrm{mM}$ sodium phosphate buffer, $\mathrm{pH}$ 7.1 (1: 1.5). Nitrate content in the extracts was reduced to nitrite by the addition of nitrate reductase enzyme and NADPH as a cofactor. Then the sample was incubated for $2 \mathrm{~h}$ at room temperature before addition of the Griess reagent and incubation for $10 \mathrm{~min}$. The concentration of nitrate plus nitrite was measured spectrophotometrically at $\lambda=540 \mathrm{~nm}$. Quantification was performed using a nitrate and nitrite standard curve in the range of 0 to $75 \mu \mathrm{M}$.

\subsection{Determination of NO content}

The isolated DG were homogenized in $60 \mathrm{mM}$ Tris- $\mathrm{HCl}$ buffer, $100 \mathrm{mM} \mathrm{KCl}$, pH 7.0 (1:0.7), supplemented with the spin trap solution, 
$10 \mathrm{mM}$ sodium- $N$-methy-D-glucamine dithiocarbamate (MGD):1 mM $\mathrm{FeSO}_{4}$. The supernatant was immediately transferred to Pasteur pipettes for EPR measurements. The spectra were recorded at room temperature $\left(18^{\circ} \mathrm{C}\right)$ in the EPR spectrometer described above, operating at $9.76 \mathrm{GHz}$ microwave frequency, $20 \mathrm{~mW}$ microwave power, $50 \mathrm{kHz}$ modulation frequency, $5.983 \mathrm{G}$ modulation amplitude, $200 \mathrm{G}$ field scan, $327.68 \mathrm{~ms}$ time constant, 83.886 s sweep time. Quantification of the spin adduct was performed using an aqueous solution of TEMPOL as described above.

\subsection{Statistical analyses}

Data in the text and tables are expressed as mean \pm S.E.M. Statistical tests were carried out using Statview for Windows, ANOVA, SAS Institute Inc., version 5.0.

\section{Results}

Fully aerated natural seawater used to maintain experimental $M$. arenaria in the laboratory had a content of Fe of $10.7 \pm 0.2 \mathrm{nM}$. The animals were kept in this water for more than 2 months without mortality. DG of $M$. arenaria collected in the natural habitat and kept in the aquaria over 2 months had a total Fe content of $39 \pm 4 \mathrm{ng} \mathrm{Fe} / \mathrm{mg}$ FM, evaluated spectrophotometrically after enzymatic digestion. To further corroborate this start value, Fe content was measured by atomic absorption, and the obtained value ( $49 \pm 10 \mathrm{ng} \mathrm{Fe} / \mathrm{mg} \mathrm{FM})$ did not differ significantly from the value measured spectrophotometrically. The content of Fe in DG of bivalves exposed to seawater supplemented with $9 \mu \mathrm{M}$ Fe over 9 days was $45 \pm 11 \mathrm{ng}$ Fe/mg FM, showing that even an increase by close to 1000 -fold did not lead to significantly higher Fe levels in the DG. Exposure to $500 \mu \mathrm{M}$ dissolved Fe in natural seawater resulted in a significant increase in DG total Fe content after 9 days. Until day 17 (Fig. 1) concentrations increased further, close to tripling the control values. Survival of the animals was not significantly affected by high Fe exposure during the initial 17 days of the treatment (1-2 deaths out of 22 animals). Mortality increased, however, drastically by day 18 when $60-80 \%$ of the animals from the Fe treatment died so that the experimental protocol was stopped after day 17.

In spite of the fact that previous data on alterations in the activity of antioxidant enzymes in other molluscs (Alves de Almeida et al., 2004) would suggest that glutathione metabolism could be affected by Fe exposure, total glutathione content, the GSSG/GSH ratio and

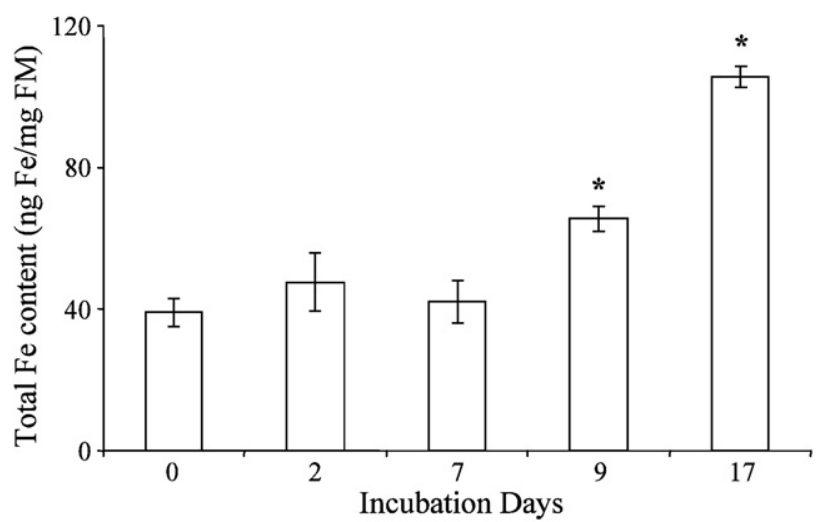

Fig. 1. Kinetic profile of the total Fe content in DG from M. arenaria exposed to seawater supplemented with $500 \mu \mathrm{M}$ Fe. Fe content was assessed spectrophotometrically, as indicated in the Material and Methods Section. Twenty animals (20) (4 animals per group) were employed in each experiment. Measurements were performed by duplicate. *significantly different from the value at day 0 with $p<0.01$. ANOVA.
Table 1

Effect of Fe supplementation on the GSSG/GSH ratio in DG from M. arenaria.

\begin{tabular}{lcr}
\hline Fe exposure & Day 0 & \multicolumn{1}{c}{ Day 17} \\
\hline Total glutathione content (nmol/mg FM) & $1.2 \pm 0.1$ & $1.4 \pm 0.3$ \\
GSSG/GSH ratio & $0.5 \pm 0.1$ & $0.8 \pm 0.3$ \\
$\Delta E(\mathrm{mV})$ & $-215 \pm 3$ & $-208 \pm 4$ \\
\hline
\end{tabular}

Six animals (6) were employed in each experiment performed by duplicate. Data from 3 independent experiments are shown.

tissue redox potential $(\Delta E)$ in the DG was no significantly changed by high Fe treatment (Table 1 ).

DCFH-DA oxidation rate by DG homogenate was evaluated as an index for the chemical ROS generation capacity. Data in Fig 2A indicate that ROS generation capacity followed a biphasic response with a significantly higher value after 2 days, as compared to values in DG homogenates from animals at day 0 of exposure to Fe. A second
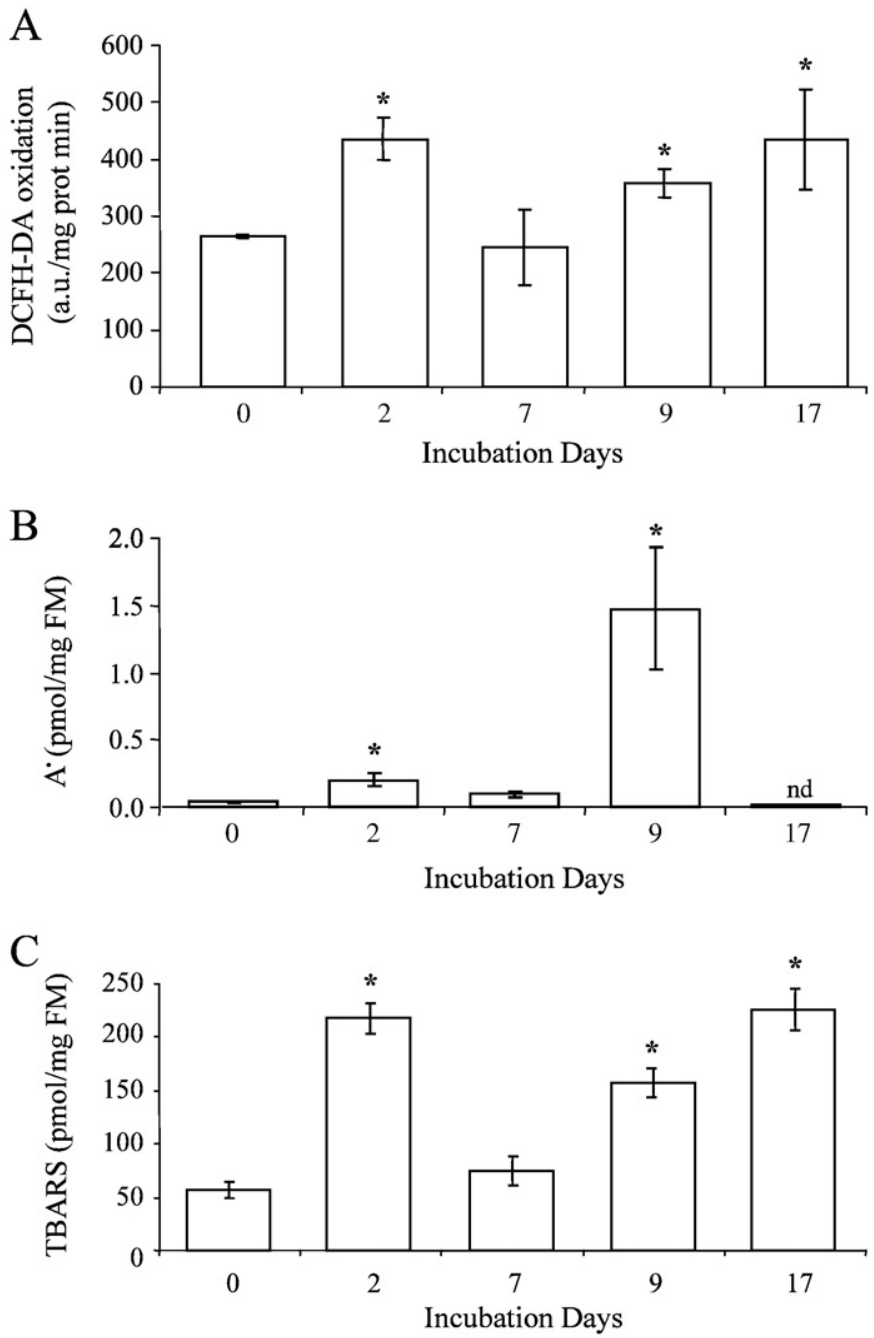

Fig. 2. Kinetic profile of oxidative stress and oxidative damage indicators in DG from $M$. arenaria. A. ROS generation rate, assessed ad DCFH-DA oxidation rate in tissue from animals exposed to seawater supplemented with $500 \mu \mathrm{M}$ Fe. Twenty animals (20) ( 4 animals per group) were employed in each experiment. Measurements were performed by duplicate. *significantly different from the value at day 0 with $p<0.05$. ANOVA. B. A content in tissue from animals exposed to seawater supplemented with $500 \mu \mathrm{M}$ Fe. Fifteen animals (15) (3 animals per group) were employed in each experiment. Measurements were performed by duplicate. nd stands for non-detectable signal. *significantly different from the value at day 0 with $p<0.01$. ANOVA. C. TBARS content in tissue from animals exposed to seawater supplemented with $500 \mu \mathrm{M}$ Fe. Twenty animals (20) (4 animals per group) were employed in each experiment. Measurements were performed by duplicate. *significantly different from the value at day 0 with $p<0.001$. ANOVA. 
increase on DCFH-DA oxidation occurred by day 9 of treatment. The ratio $\mathrm{A} \cdot$ content $/ \mathrm{AH}^{-}$content is an index of the oxidative stress in the hydrophilic fraction (Kozak et al., 1997; Estévez et al., 2001; Galleano et al., 2002). Typical EPR spectra of A• were recorded in DG from both, control and Fe-exposed animals. The EPR spectrum showed the characteristic two lines at $g=2.005$ and $a_{\mathrm{H}}=1.8 \mathrm{G}$, in agreement with computer simulated signals obtained using the parameters mentioned above. Moreover, DMSO did not form a spin adduct by itself. A biphasic increase of the $A \cdot$ content in DG of Fe-exposed $M$. arenaria was detected on day 2 (4-fold over the $A \bullet$ value on 0 day) and day 9 (25-fold over the $\mathrm{A} \cdot$ content on 0 day) (Fig. 2B). The $\mathrm{AH}^{-}$content in the DG from animals exposed to excess Fe was not significantly different from the content in control bivalves $(0.48 \pm 0.01 \mathrm{nmol} /$ $\mathrm{mg}$ FM) at all studied time points. The ratio $\mathrm{A} \cdot$ content $/ \mathrm{AH}^{-}$content is $0.9 \pm 0.2,4.2 \pm 0.8,1.9 \pm 0.7$ and $20 \pm 1.5$ (a.u. $10^{-4}$ ) for days $0,2,7$ and 9 of exposure of excess $\mathrm{Fe}$, respectively, showing significant increases at day 2 and 9 over day 0 of treatment.

As lipid oxidation is an important indicator of oxidative tissue damage associated with Fe accumulation, TBARS content was analyzed in DG. Again, the data in Fig. 2C followed the biphasic accumulation profile. After 2 days of exposure to Fe, TBARS content in DG showed a significant increase by approximately 3.8 -fold compared to control values. This increase was followed by a decrease to control values at treatment day 7. Afterwards TBARS concentration increased constantly until day 17 (Fig. 2C).

Data in Fig. 3 show that the LIP in DG tissue increased on day 7 of exposure to high dissolved Fe concentration. By day 9, the LIP increase was accompanied by a significant induction of the oxidative stress signals, ROS and $\mathrm{A}^{*}$ content and correlated with the final increase of tissue TBARS content. Since the labile Fe in the hemocytes may represent one of the pathways for Fe elimination from the DG to the shell where it is incorporated into the organic matrix, the LIP content in the hemocytes was measured. Data in Fig. 4 indicated that the LIP in the hemocytes had increased significantly by day 7 (140\%), and values increased further until exposure day 17 (166\%). Contrary, oxidative stress effects measured on day 2 of treatment cannot be attributed to a significant increase of the LIP, since neither total Fe content nor the LIP were enhanced over the initial values in the 0 day exposure group.

SOD activity shown in Fig. 5 were constant over an initial period of 0 to 7 days of exposure to $\mathrm{Fe}$, and decreased significantly at days 9 and 17 of exposure compared to controls. The $\mathrm{H}_{2} \mathrm{O}_{2}$ scavenging antioxidant, CAT increased after 2 days of treatment compared to controls (day 0 ) but the activity was back to control level on day 7 of exposure (Fig. 5). CAT activity was, however, increased again on day 9 of exposure compared to controls (Fig. 5).

We further investigated the reactive nitrogen species content, mainly NO, in DG throughout the experimental time period. The content of nitrate and nitrite, as indicator of tissue NO content, decreased by

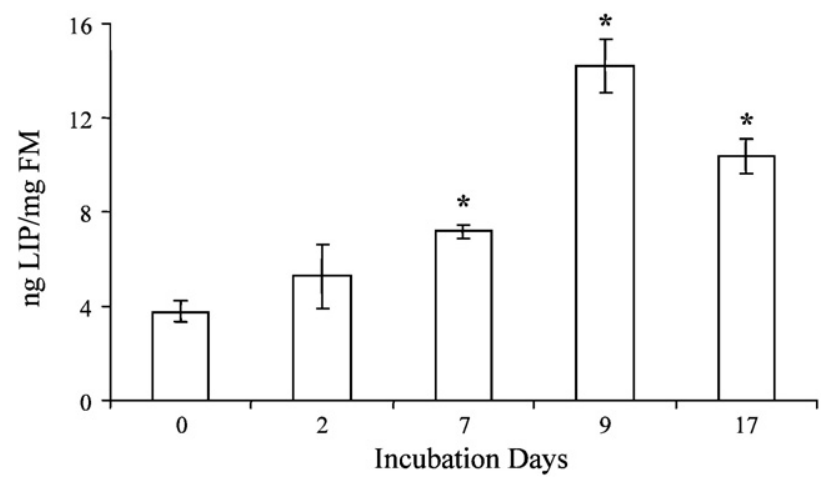

Fig. 3. Kinetic profile of LIP content in DG from $M$. arenaria exposed to seawater supplemented with $500 \mu \mathrm{M}$ Fe. Twenty animals (20) (4 animals per group) were employed in each experiment. Measurements were performed by duplicate. *significantly different from the value at day 0 with $p<0.05$. ANOVA. approximately $85 \%$ on day 2 with no further alterations over the 17 day lasting experimental period (Table 2). The nitrate and nitrite contents might however overestimate the intracellular NO content since both are small and stable inorganic molecules that can freely enter cells through the membrane from the extracellular fluid. Thus, NO content in DG homogenates was assessed directly by EPR spin trapping with MGD-Fe at room temperature. The EPR signal is characterized by an isotropic triplet signal at $g=2.03$ and $a_{\mathrm{N}}=12.5 \mathrm{G}$, and its features are unique and enable a fingerprint-like identification of NO (Fig. 6). The extra peak detected in DG which is not visible in the computer-simulated signal seems to be due to the formation of the complex $\mathrm{Cu}-\mathrm{MGD}$, as previously reported (Gisone et al., 2003) (Fig. 6, line d). The NO-dependent EPR signal was neither detectable in the absence of homogenate nor in the presence of boiled homogenate (Fig. 6). The content of NO was significantly lower (60\%) in DG of animals exposed to Fe excess over 2 days, as compared to DG of animals not exposed to Fe. No further changes were recorded over the rest of the treatment time (Table 2), in agreement with the time pattern of nitrate and nitrite content.

\section{Discussion}

Even after 17 days of treatment when Fe concentrations were drastically elevated over the natural Fe content in coastal seawater, the Fe content in M. arenaria DG was raised to only $38 \%$ of the in situ Fe concentration in DG of the Antarctic soft shell clam L. elliptica (Malanga et al., 2008) (Table 3). This Antarctic species is permanently exposed to high environmental Fe concentrations during approximately 40 years of species specific lifespan. By contrast, $M$. arenaria died already after 18 days of exposure in Fe enriched seawater, suggesting storage capacities as well as physiological tolerance to be overruled by Fe toxicity. For $M$. arenaria the rapid increase apparently represented a Fe overload situation, entailing severe oxidative stress and resulting in damage to cellular structures, severe enough to compromise survival. The slow accumulation of Fe may reflect the normal bioaccumulation of dissolved Fe into DG and possibly forms a first line of defense in $M$. arenaria against uncontrolled Fe uptake.

An initial response with elevated oxidative stress parameters in the DG tissue was visible by day 2 of Fe exposure, however by day 7 all parameters were back to control values. This initial phase of elevated oxidative stress, occurring before significant Fe accumulation was observed in DG of exposed animals, can possibly be attributed to physiological stress under the experimental exposure conditions. We did not measure the metabolic rates, but it is possible that Fe exposure triggers an initial stress response including accelerated respiration as the animals are pumping to rid themselves of the inflowing $\mathrm{Fe}$ enriched sea water.

Chemically the initial phase of stress response in DG tissue to Fe exposure at day 2, could be explained by i) A direct effect of Fe. However, as the total Fe content was not significantly increased over the 0 day levels until day 7 of Fe exposure, it seems that intracellular Fe cannot directly explain the cellular response. ii) An indirect effect of excess Fe. During the last years, the investigation of the mechanism involved in the oxidation of $\mathrm{Fe}^{2+}$ in seawater has been studied. The mechanism proposed by King et al. (1995) considered the generation of hydrogen peroxide, as shown in reaction 2.

$$
\begin{aligned}
& \mathrm{Fe}^{2+}+\mathrm{O}_{2} \stackrel{k_{1}}{\longrightarrow} \mathrm{Fe}^{3+}+\mathrm{O}_{2}^{\cdot-} \\
& 2 \mathrm{H}^{+}+\mathrm{Fe}^{2+}+\mathrm{O}_{2}^{\cdot-} \stackrel{k_{2}}{\longrightarrow} \mathrm{Fe}^{3+}+\mathrm{H}_{2} \mathrm{O}_{2}
\end{aligned}
$$

Hydrogen peroxide is a good candidate for triggering cellular responses since it is the most stable of the reactive intermediates of oxygen reduction (Boveris, 1998). $\mathrm{H}_{2} \mathrm{O}_{2}$ diffuses freely into the tissue and increases the oxidative stress (measured as DCFH-DA oxidation, $\mathrm{A}^{*}$ content) and further causes oxidative damage assessed as TBARS 
A

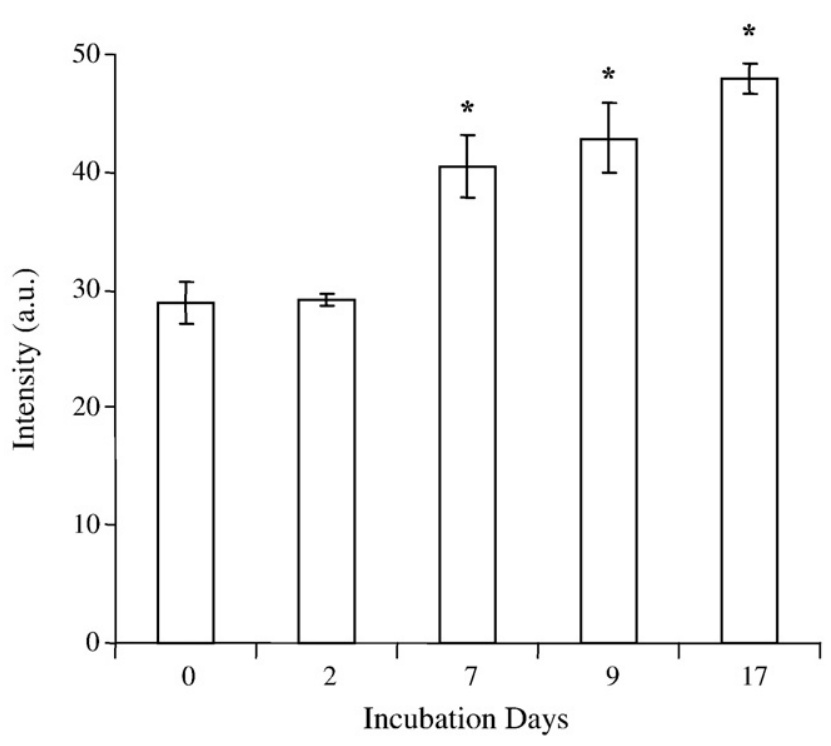

B

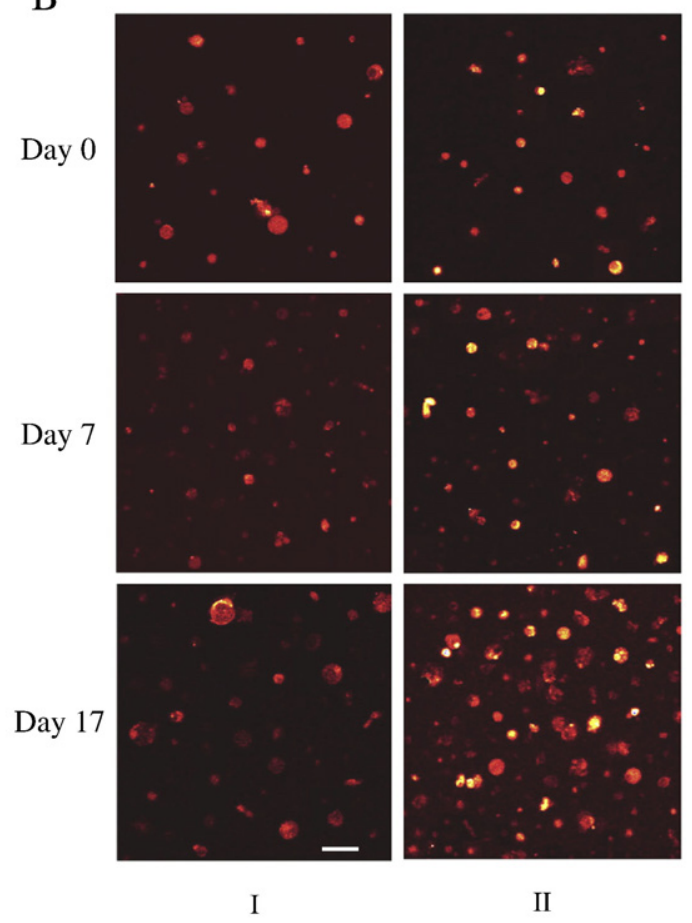

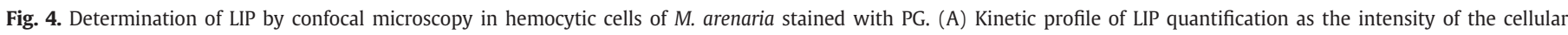

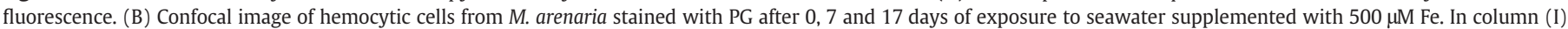

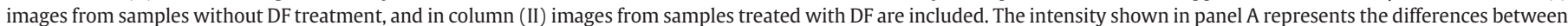
the number of fluorescence cells recorded in columns I and II. Scale bar $10 \mu \mathrm{m}$. *significantly different from the value at day 0 with $p<0.01$. ANOVA.

content. $\mathrm{H}_{2} \mathrm{O}_{2}$ is especially toxic through Fenton reaction with $\mathrm{Fe}^{2+}$ where it gives rise to the extremely reactive hydroxyl radical (reaction 3)

$\mathrm{Fe}^{2+}+\mathrm{H}_{2} \mathrm{O}_{2} \stackrel{k_{3}}{\longrightarrow} \mathrm{Fe}^{3+}+\mathrm{OH}^{-}+\mathrm{HO}^{\circ}$

In this first phase, $\mathrm{H}_{2} \mathrm{O}_{2}$ induced oxidative stress may have triggered the endogenous antioxidant system in such a manner that by day 7 of exposure to excess Fe both, $A \cdot$ and TBARS content, were again reduced to the starting values. The antioxidant enzyme most clearly triggered by this initial oxidative stress was the $\mathrm{H}_{2} \mathrm{O}_{2}$-decomposing CAT, whereas activity SOD was not further induced. The reduction of SOD activity following day 9 of exposure to Fe probably supports the oxidative stress situation at the end of the exposure experiment. On day 17 only one half of the SOD activity in control animal DG was recorded. Further,

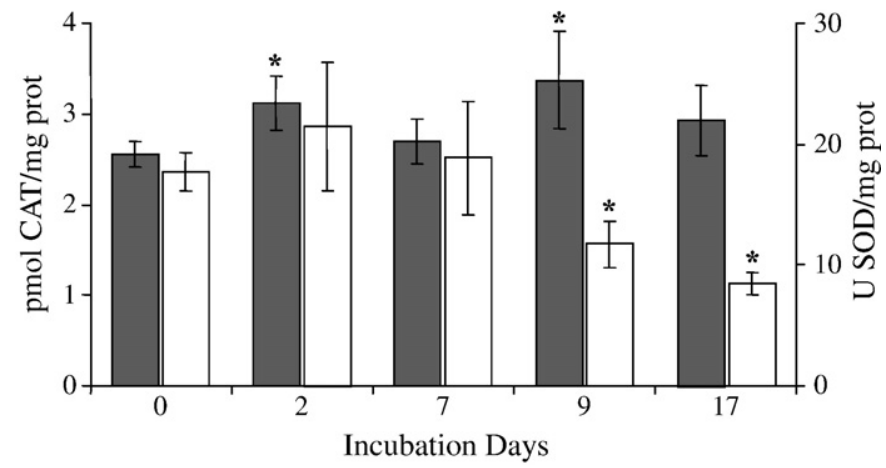

Fig. 5. Determination of CAT concentration $(\square)$ and SOD activity $(\square)$ in DG of $M$. arenaria exposed to seawater supplemented with $500 \mu \mathrm{M}$. Fifteen animals (15) (3 animals per group) were employed in each experiment. Measurements were perfomed by triplicate. *significantly different from the value at day $0 p<0.1$. induction of other protective mechanisms, such as metallothioneins, might act as effective transient control of heavy metal effects during the initial phase of heavy metal exposure, see also Viarengo et al. (1999) and Alves de Almeida et al. (2004), but this protective mechanism was not analyzed in our study.

The steady state concentration of the LIP could be described by the following equation (Eq 5), where each term refers to the change in the concentration of Fe bound to each physiological available Fe-chelator in cells.

$$
\begin{aligned}
\frac{d[\mathrm{Fe}]}{d \mathrm{t}}= & \left(\frac{d[\mathrm{Fe}]}{d \mathrm{t}}\right)_{\text {citrate }}+\left(\frac{d[\mathrm{Fe}]}{d \mathrm{t}}\right)_{\mathrm{ATP}}+\left(\frac{d[\mathrm{Fe}]}{d \mathrm{t}}\right)_{\mathrm{ADP}}+\left(\frac{d[\mathrm{Fe}]}{d \mathrm{t}}\right)_{\text {oxalate }} \\
& +\left(\frac{d[\mathrm{Fe}]}{d \mathrm{t}}\right)_{\mathrm{NO}}+\left(\frac{d[\mathrm{Fe}]}{d \mathrm{t}}\right)_{\text {other physiological chelators }}
\end{aligned}
$$

NO can readily diffuse across cell membranes and part of its functions is causing Fe release from the cell (Radi et al., 1995). NO can bind to Fe and endogenous thiols generating dinitrosyl-Fe, dinitrosyldiglutathionyl-Fe or dinitrosyl-glutathionyl Fe complexes among

Table 2

$\mathrm{NO}$ and $\mathrm{NO}_{2}{ }^{-}+\mathrm{NO}_{3}{ }^{-}$content in DG of $M$. arenaria exposed to $500 \mu \mathrm{M}$ Fe.

\begin{tabular}{llc}
\hline Treatment (day) & $\mathrm{NO}$ & $\mathrm{NO}_{2}{ }^{-}+\mathrm{NO}_{3}{ }^{-}$ \\
\cline { 2 - 3 } & $(\mathrm{pmol} / \mathrm{mg} \mathrm{FM})$ & \\
\hline 0 & $99 \pm 3$ & $613 \pm 38$ \\
2 & $41 \pm 7^{\mathrm{a}}$ & $93 \pm 22^{\mathrm{a}}$ \\
7 & $42 \pm 17^{\mathrm{a}}$ & $95 \pm 7^{\mathrm{a}}$ \\
9 & $43 \pm 2^{\mathrm{a}}$ & $96 \pm 11^{\mathrm{a}}$ \\
17 & $31 \pm 1^{\mathrm{a}}$ & $95 \pm 5^{\mathrm{a}}$ \\
\hline
\end{tabular}

For the determination of nitrates and nitrites content, twenty five animals ( 5 animals per group) were employed. The measurements were performed in duplicates. For the determination of NO, fifteen animals ( 3 animals per group) were employed.

a Significantly different from the value measured in day $0, p<0.001$. ANOVA. 


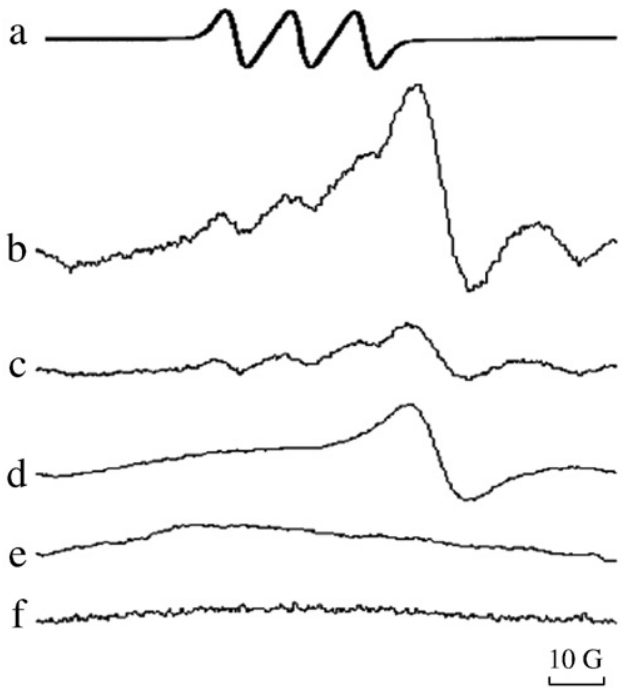

Fig. 6. NO detection in DG of M. arenaria. (a) Computer-simulated spectrum employing the parameters, $g=2.03$ and $a_{\mathrm{N}}=12.5 \mathrm{G}$. (b) spectrum at day 0 , (c) spectrum at day 9 , (d) spectrum of $\mathrm{Cu}^{2+} 50 \mu \mathrm{M}$ with MGD-Fe, (e) spectrum from boiled DG; and (f) reactive blank spectrum (no animal tissue added).

other nitrosyl-Fe complexes (Pedersen et al., 2007) as indicated in (Eq 6).

$$
\begin{aligned}
\left(\frac{d[\mathrm{Fe}]}{d \mathrm{t}}\right)_{\mathrm{NO}}= & \left(\frac{d[\mathrm{Fe}]}{d \mathrm{t}}\right)_{\text {dinitrosyl complex }}+\left(\frac{d[\mathrm{Fe}]}{d \mathrm{t}}\right)_{\text {dinitrosyl-diglutathionyl complex }} \\
& +\left(\frac{d[\mathrm{Fe}]}{d \mathrm{t}}\right)_{\text {dinitrosyl-glutathionyl complex }} \\
& +\left(\frac{d[\mathrm{Fe}]}{d \mathrm{t}}\right)_{\text {other physiological complexes }}
\end{aligned}
$$

Thus, NO could favor Fe release from the cell avoiding its accumulation by the formation of the complexes described above that can leave the cell through the membrane. In agreement with the hypothesis that NO is part of the system controlling Fe uptake in the first instance of exposure, we showed that NO content in DG was drastically decreased by day 2 of treatment. On the other hand, NO has previously been shown to inhibit lipid peroxidation in many biological systems (Dee et al., 1991; Kanner et al., 1991; Hogg et al., 1993; Rubbo et al., 1994; Gorbunov et al., 1995; Sharpe et al., 2003) through its ability of binding catalytically active Fe (Radi et al., 1995). Thus, the decreased NO content in DG measured by day 2 of exposure to excess Fe could also play a role in the increase in lipid peroxidation, as previously proposed for other biological systems (Radi et al., 1995). Also, it should not be discarded that the activity of NOS-like enzymes could be partially inhibited by the initial radical-dependent stress triggered by the Fe treatment.

The LIP increases in hemocytes and DG by day 7 of experimental exposure to Fe, suggesting that the cellular mechanisms that limit Fe uptake were overwhelmed. Once the LIP has increased, the catalytically

Table 3

Comparison of Fe-dependent oxidative parameters between DG of L. elliptica and $M$. arenaria.

\begin{tabular}{clll}
\hline & $\begin{array}{c}\text { M. arenaria day } \\
17+500 \mu \mathrm{M} \mathrm{Fe}\end{array}$ & $\begin{array}{l}\text { L. elliptica } \\
\text { natural habitat }\end{array}$ & Ref. \\
\hline $\begin{array}{c}\text { Total Fe content } \\
(\mathrm{nmol} \mathrm{Fe} / \mathrm{mg} \mathrm{FM})\end{array}$ & $1.88 \pm 0.06$ & $5.00 \pm 1.00^{\mathrm{a}}$ & Malanga et al. (2008) \\
$\begin{array}{c}\text { TBARS } \\
(\mathrm{pmol} / \mathrm{mg} \mathrm{FM})\end{array}$ & $226 \pm 20$ & $420 \pm 70^{\mathrm{a}}$ & Malanga et al. (2008) \\
\hline
\end{tabular}

a Significantly different from the value measured at day $17+500 \mu \mathrm{M}$ in M. arenaria, $p<0.01$. active Fe is able to efficiently catalyze Fenton (Boveris, 1998; Pierre and Fontecave, 1999) and Haber-Weiss reactions (Rauen et al., 2000; Livingstone, 2001, Eqs. 2 and 3) and consistently and drastically accelerated $A \cdot$ formation and accumulation of TBARS. TBARS reflects the accumulation of the oxidized substances, including MDA, which are generated over a period, whereas $A^{*}$ represents the instantaneous metabolic generation of reactive species. Thus, by day 17 when the cellular metabolism was severely disturbed, TBARS content in DG was still high as compared to control animals maintained in water not supplemented with Fe. Contrary, A $\bullet$ content was almost non-detectable in animals after 17 days of exposure, suggesting a metabolic collapse due to oxidative damage, that included the enzymes responsible for ROS generation. This second phase of the response seems to reflect fatal damage as a consequence of the exhaustion of cellular defense by $\mathrm{Fe}$ overload, most clearly seen in the SOD activity, which would led to enhanced death rates in the Fe-exposed group.

The index of lipid radical content/ $\alpha$-tocopherol content can be understood as indicator of the damage/protection ratio (Galleano et al., 2002; Malanga et al., 2009). This index was $1.6 \pm 0.3$ and $1.3 \pm 0.2$ for $L$. elliptica and $M$. arenaria respectively. In both cases animals were taken directly from the natural habitat (Puntarulo et al., 2005). These data suggest that chronically high Fe content in Antarctic species is adequately controlled by endogenous mechanisms in L. elliptica, whereas these mechanisms not seem to have developed in $M$. arenaria, a species coming from low Fe environments. In conclusion, the data presented here speak for an ability to minimize Fe uptake and limit oxidative damage in molluscs, adapted to low natural Fe levels, when exposed to excess dissolved $\mathrm{Fe}$ in seawater. However, when the endogenous mechanisms in charge of regulating $\mathrm{Fe}$ uptake are overwhelmed by polluting concentrations of Fe, survival is affected which documents the vicious effects of environmental contamination with transition metals.

\section{Acknowledgements}

This study was supported by grants from the University of Buenos Aires, CONICET and a DAAD fellowship for PMG. SP is career investigator from CONICET and PMG is a fellow from the University of Buenos Aires.

\section{References}

Abele, D., Heise, K., Pörtner, H.O., Puntarulo, S., 2002. Temperature-dependence of mitochondrial function and production of reactive oxygen species in the intertidal mud clam Mya arenaria. J. Exp. Biol. 205, 1831-1841.

Aebi, H., 1984. Catalase in vitro. Methods Enzymol. 105, 121-126.

Ahearn, G.A., Mandal, P.K., Mandal, A., 2004. Mechanisms of heavy-metal sequestration and detoxification in crustaceans: a review. J. Comp. Physiol. 174 (6), 439-452.

Alves de Almeida, E., Miyamoto, S., Celso Dias Bainy, A., Gennari de Medeiros, M.H., Di Mascio, P., 2004. Protective effect of phospholipid hydroperoxide glutathione peroxidase (PHGPX) agaist lipid peroxidation in mussels Perna perna exposed to different metals. Mar. Pollut. Bull. 49, 386-392.

Boveris, A., 1998. Biochemistry of free radicals: from electrons to tissues. Medicina 54, 350-356.

Bralet, J., Schreiber, L., Bouvier, C., 1992. Effect of acidosis and anoxia on iron delocalization from brain homogenates. Biochem. Pharmacol. 43 (5), 971-979.

Cooper, C.E., 1999. Nitric oxide and iron proteins. Biochim. Biophys. Acta 1411, 290-309.

Darbari, D., Loyevsky, M., Gordeuk, V., Kark, J.A., Castro, O., Rana, S., Apprey, V., Kurantsin-Mills, J., 2003. Fluorescence measurements of the labile iron pool of sickle erythrocytes. Blood 102, 357-364.

Davis, K.L., Martin, E., Turko, I.V., Murad, F., 2001. Novel effects of nitric oxide. Annu. Rev. Pharmacol. Toxicol. 41, 203-236.

Dee, G., Rice-Evans, C., Obeyesekera, S., Meraji, S., Jacobs, M., Bruckdorfer, K.R., 1991. The modulation of ferryl myoglobin formation and its oxidative effects on low density lipoproteins by nitric oxide. FEBS Lett. 294, 38-42.

Estévez, M.S., Malanga, G., Puntarulo, S., 2001. Iron-dependent oxidative stress in Chlorella vulgaris. Plant Sci. 161, 9-17.

Estévez, M.S., Abele, D., Puntarulo, S., 2002. Lipid radical generation in polar (Laternula elliptica) and temperate (Mya arenaria) bivalves. Comp. Biochem. Physiol. 132 B, 729-737.

Fariss, M.W., Reed, D.J., 1987. High-performance liquid chromatography of thiols and disulfides: dinitrophenol derivatives. Meths Enzymol. 143, 101-109. 
Gallagher, E.P., Canadá, A.T., DiGiulio, R.T., 1992. The protective role of glutathione in chlorothalonil-induced toxicity to channel catfish. Aquat. Toxicol. 23, 155-168.

Galleano, M., Aimo, L., Puntarulo, S., 2002. Ascorbyl radical / ascorbate ratio in plasma from iron overloaded rats as oxidative stress indicator. Toxicol. Lett. 133, 193-201.

Geyer, H., Sheehan, P., Kotzias, D., Freitag, D., Korte, F., 1982. Prediction of ecotoxicological behaviour of chemicals: relationship between physico-chemical properties and bioaccumulation of organic chemicals in the mussel Mytilus edulis. Chemosphere 11, 1121-1134.

Gisone, P., Boveris, A.D., Dubner, D., Perez, M.R., Robello, E., Puntarulo, S., 2003. Early neuroprotective effect of nitric oxide in developing rat brain irradiated in utero. Neurotoxicology 24, 245-253.

González, P.M., Abele, D., Puntarulo, S., 2008a. Iron and radical content in Mya arenaria. Possible sources of NO generation. Aquat. Toxicol. 89, 122-128.

González, P.M., Malanga, G., Puntarulo, S., 2008b. Ferritin and labile iron pool in limpets from the Beagle Channel. In: Svensson, E.P. (Ed.), Aquatic Toxicology Research Focus, 9. Nova Science Publishers Inc, New York, pp. 177-188.

Gorbunov, N.V., Osipov, A.N., Day, B.W., Zayas-Rivera, B., Kagan, V.E., Elsayed, N.M., 1995. Reduction of ferrylmyoglobin and ferrylhemoglobin by nitric oxide: a protective mechanism against ferryl hemoprotein-induced oxidations. Biochemistry 34, 6689-6699.

Hering, J., Morel, F., 1988. Kinetics of trace metal complexation: role of alkaline-earth metals. Environ. Sci. Technol. 22, 1469-1478.

Hogg, N., Kalyanaraman, B., Joseph, J., Struck, A., Parthasarathy, S., 1993. Inhibition of low-density lipoprotein oxidation by nitric oxide. Potential role in atherogenesis. FEBS Lett. 334, 170-174.

Kanner, J., Harel, S., Granit, R., 1991. Nitric oxide as an antioxidant. Arch. Biochem. Biophys. 289, 130-136.

King, D.W., Lounsbury, H.A., Millero, F.J., 1995. Rates and mechanisms of Fe (II) oxidation at nanomolar total iron concentrations. Environ. Sci. Technol. 29, 818-824.

Kotake, Y., Tanigawa, T., Tanigawa, M., Ueno, I., Randel Allen, D., Lai, C.-S., 1996. Continuous monitoring of cellular nitric oxide generation by spin trapping with an iron-dithiocarbamate complex. Biochim. Biophys. Acta 1289, 362-368.

Kozak, R.G., Malanga, G., Caro, A., Puntarulo, S., 1997. Ascorbate free radical content in photosynthetic organisms alter exposure to ultraviolet-B. Rec. Res. Dev. Plant Physiol. 1, 233-239.

Kutnink, M.A., Hawkes, W.C., Schaus, E.E., Omaye, S.T., 1987. An internal standard method for the unattended high-performance liquid chromatographic analysis of ascorbic acid in blood components. Anal. Biochem. 166, 424-430.

Livingstone, D.R., 2001. Contaminant-stimulated reactive oxygen species production and oxidative damage in aquatic organisms. Mar. Pollut. Bull. 42, 656-666.

Lowry, O.H., Rosebrough, N.J., Farr, A.L., Randall, R.J., 1951. Protein measurement with the Folin phenol reagent. J. Biol. Chem. 193, 265-275.

Malanga, G., González, P.M., Estévez, M.S., Abele, D., Puntarulo, S., 2008. Oxidative stress in Antarctic algae and molluscs. In: Wiencke, C., Ferreyra, G.A., Abele, D., Marenssi, S. (Eds.), The Antarctic ecosystem of Potter Cove, King-George Island (Isla 25 de Mayo). Bremerhaven, Germany, pp. 208-215.

Malanga, G., Pérez, A., Calvo, J., Puntarulo, S., 2009. The effect of seasonality on oxidative metabolism in the sea urchin Loxechinus albus. Mar. Biol. 156, 763-770.
McCord, J.M., Fridovich, I., 1969. Superoxide dismutase. Enzymatic function for erithrocuprein (hemocuprein). J. Biol. Chem. 244, 6019-6055.

Pedersen, J.Z., De Maria, F., Turrella, P., Federeci, G., Mattei, M., Fabrini, R., Dawood, K., Massimi, M., Caccuri, A.M., Ricci, G., 2007. Glutathione transferases sequester toxic dinitrosyl-iron complexes in cells. J. Biol. Chem. 282, 6364-6371.

Pierre, J.L., Fontecave, M., 1999. Iron and activated oxygen species in biology: the basic chemistry. Biometals 12, 195-199.

Pörtner, H.O., Boutilier, R.G., Tang, Y., Toews, D.P., 1990. Determination of intracellular $\mathrm{pH}$ and $\mathrm{PCO}_{2}$ after metabolic inhibition by fluoride and nitrilotriacetic acid. Respir Physiol. 81, 255-274.

Puntarulo, S., Estévez, M.S., Malanga, G., Calvo, J., 2005. Oxidative stress in invertebrates. In: Thatje, S., Calcagno, A., Arntz, W.E. (Eds.), Evolution of the Antarctic Fauna. Extended Abstracts of the IBMANT/ANDEEP International Symposium and Workshop 2003, pp. 80-82.

Radi, R., Rubbo, H., Freeman, B.A., 1995. The double-edge action of nitric oxide on free radical mediated oxidations. Ciencia e Culture J. Braz. Assoc. Adv. Sci. 47, 288-296.

Rauen, U., Petrat, F., Tongju, L., De Groot, H., 2000. Hypothermia injury/cold induced apoptosis - evidence an increase of chelatable iron causing oxidative injury in spite of low $\mathrm{O}_{2} / \mathrm{H}_{2} \mathrm{O}_{2}$ formation. FASEB J. 14, 1953-1964.

Robello, E., Galatro, A., Puntarulo, S., 2007. Iron role in oxidative metabolism of soybean axes upon growth effect of iron overload. Plant Sci. 172, 939-947.

Rubbo, H., Radi, R., Trujillo, M., Telleri, R., Kalyanaramann, B., Barnes, S., Kirk, M., Freeman, B.A., 1994. Nitric oxide regulation of superoxide and peroxynitritedependent lipid peroxidation. Formation of novel nitrogen-containing oxidized lipid derivatives. J. Biol. Chem. 269 (42), 26066-26075.

Schafer, F.Q., Buettner, G.R., 2001. Redox environment of the cell as viewed through the redox state of the glutathione disulfide/glutathione couple. J. Free Radic. Biol. Med. 30, 1191-1212.

Sharpe, M.A., Robb, S.J., Clark, J.B., 2003. Nitric oxide and Fenton/Haber-Weiss chemistry: nitric oxide is a potent antioxidant at physiological concentrations. J. Neurochem. 87 (2), 386-394.

Storch, D., Abele, D., Pörtner, H.O., 2001. The effect of hydrogen peroxide on isolated body wall of the lugworm Arenicola marina at different extracellular pH levels. Comp. Biochem. Physiol. 128C, 391-399.

Templeton, D.M., Liu, Y., 2003. Genetic regulation of cell function in response to iron overload or chelation. Biochim. Biophys. Acta 1619 (2), 113-124.

Tynan, S., Eggins, S., Kinsley, L., Welch, S.A., Kirste, D., 2005. Mussel shells as environmental tracers: an example from the loveday basin. In: Roach, I.C. (Ed.) Ten years of CRC LEME. CRC LEME, p. 314-117.

Uchiyama, M., Mihara, M., 1978. Determination of malonaldehyde precursor in tissues by thiobarbituric acid test. Anal. Biochem. 86, 271-278.

Verdon, C.P., Burton, B.A., Prior, R.L., 1995. Sample pretreatment with nitrate reductase and glucose-6-phosphate dehydrogenase quantitatively reduces nitrate while avoiding interference by $\mathrm{NADP}^{+}$when the Griess reaction is used to assay for nitrite. Anal. Biochem. 224 (2), 502-508.

Viarengo, A., Burlando, B., Cavaletto, M., Marchi, B., Ponzano, E., Blasco, J., 1999. Role of metallothionein agaist oxidative stress in the mussel Mytilus galloprovincialis. Am. J. Physiol. Regul. Integr. Comp. Physiol. 277, 1612-1619. 